\title{
Combining endovascular and neurosurgical treatments of high-risk dural arteriovenous fistulas in the lateral sinus and the confluence of the sinuses
}

\author{
Katsuya Goto, M.D., Ph.D., Prijo Sidipratomo, M.D., Noboru Ogata, M.D., Toru Inoue, M.D., and \\ Haruo Matsuno, M.D.
}

Departments of Interventional Neuroradiology and Neurosurgery, Iizuka Hospital, Iizuka, Japan

The authors describe their experience in treating dural arteriovenous fistulas (DAVFs) in the lateral sinus and the confluence of sinuses in 17 patients who presented with signs and symptoms related to intracranial hemorrhage, infarction, and diffuse brain swelling. Angiographic examination revealed three different types of DAVFs in these high-risk patients: 1) extremely high flow DAVF not associated with sinus occlusion or leptomeningeal retrograde venous drainage (LRVD); 2) localized DAVF with exclusive LRVD and without sinus occlusion; and 3) diffuse DAVF with sinus occlusion and LRVD. Because of the complex nature of these lesions, the authors adopted a staged protocol in which they combined endovascular and surgical treatments.

The authors believe that by close collaboration between endovascular therapists and vascular neurosurgeons, high-risk DAVFs in the lateral sinus and the confluence of sinuses can be successfully treated without treatment-related morbidity and mortality.

Key Words * dural arteriovenous fistula * transverse sinus $*$ sigmoid sinus $*$ embolization $*$ surgery
combined treatment

Over the last two decades, there has been increased attention paid to patients with dural arteriovenous fistulas (DAVFs) who are at high risk for the occurrence of intracranial hemorrhage and neurological disturbances. High-risk or aggressive DAVFs are characterized by the following angiographic findings:[1,2,5,17,19,20,24] inflow of a large amount of arterial blood from the dural branches of the external carotid artery (ECA), and often from those of the internal carotid artery (ICA) and the vertebrobasilar (VB) system; arterial blood supply to the fistula that is reconstituted via complex collateral channels in recurrent cases; and occlusive changes of the venous sinuses and prominent retrograde filling of the leptomeningeal veins, which often carry varices.

Of these angiographic findings, most attention has focused on venous drainage patterns. Several investigators have demonstrated that neurological manifestations relate to the venous territory and not to the features of arterial supply or to the location of the fistula.[18,21,38] By performing a metaanalysis on 100 aggressive cases of DAVF, Awad, et al.,[1] proved that leptomeningeal retrograde venous drainage (LRVD) was significantly associated with aggressive behavior of fistulas. 
Using LRVD as a key element, several classifications of DAVF have been developed with the aim of predicting the risk of catastrophic neurological manifestations.[4,6,11,20,32] The authors of the studies rationalized that patients in whom LRVD did not occur should be treated conservatively or symptomatically, whereas patients with LRVD should undergo urgent and aggressive treatment. However, all classifications are incomplete because of gaps in our knowledge of this disease.[22] Occasionally there are cases of DAVF that demonstrate aggressive behavior without the presence of LRVD.[6,8,9] Also, lesion location and extension have not been taken into consideration in these classifications. Therefore, existing classifications are not helpful in designing a treatment plan for individual cases.

Among aggressive DAVFs, the most challenging has been the treatment of DAVFs in the transverse and sigmoid sinuses (lateral sinus[22]) and in the confluence of sinuses. This is because of the strategic importance of these sinuses in intracranial venous circulation. Additonally, it is because both the endovascular and the surgical approaches have limited value because of the complexity of the angioarchitecture.[23] It is expected that treatment results will improve by combining endovascular and surgical approaches. However, few studies have been published that deal with the combined endovascular-surgical approach in a large number of patients with complex DAVFs of the transverse and sigmoid siuses.[3,7] Moreover, treatment results in earlier reports were not always satisfactory and were occasionally associated with serious complications.

The purpose of this study is to describe the use of a systemic approach in the treatment of high-risk DAVF of the lateral sinus and the confluence of sinuses in which we achieved angiographically confirmed clinical cure, with minimal treatment-associated complications.

\section{CLINICAL MATERIAL AND METHODS}

Of the 35 cases of aggressive DAVF of the lateral sinus and the confluence of sinuses treated during the past 15 years, the DAVFs, which are associated with unifocal occlusion in the lateral sinus and LRVD, were completely obliterated in 18 patients by embolizing the diseased segment of the sinus via transfemoral approach. A combined endovascular-surgical approach was performed in 17 other cases. These 17 patients are placed into three groups based on the following angiographic characteristics: extremely high flow DAVF without sinus occlusion and LRVD (Case 1); localized DAVF with exclusive LRVD (Cases 2 and 3); and DAVF with bifocal or diffuse sinus occlusion and LRVD (Cases 4-17). Embolization was performed in the patients by one of the authors (K.G.) at three university-affiliated hospitals in western Japan. Clinical signs, symptoms, imaging findings, and treatment are summarized in Tables 1 and 2. Clinical manifestations consisted of cortical abnormality of the occipital, parietal, and temporal lobes; generalized cerebral dysfunction; and increased intracranial pressure. Imaging findings were either one or two of the following: intracranial hemorrhage, infarction, or diffuse brain swelling. 


\begin{tabular}{lc|}
\hline \hline \multicolumn{1}{c}{ Findng } & No. of Patierts \\
\hline homonymous hemiano psia & 5 \\
Gerstmann syndrome & 2 \\
aphasia & 1 \\
mental de terioration & 4 \\
disturbed consciousness & 1 \\
hemi plegia & 1 \\
seizure & 2 \\
headache & 6 \\
exophthalmos & 2 \\
easily fatigued & 1 \\
tinnitus & 5 \\
subcortical hemorrhage & 7 \\
SAH & 4 \\
subdural hemormage & 1 \\
ventioular hem orrhage & 2 \\
cerebral infarct & 4 \\
diffuse train swelling & 4 \\
\hline
\end{tabular}

Nine of the patients underwent a combined endovascular-surgical approach at presentation, and the other eight had recurrent DAVFs, which had been treated previously with embolization or ligation of the feeding arteries or irradiation, or a combination of two at other hospitals.

In view of the difficulties associated with either the endovascular or the surgical approach, the authors adopted the following protocol for the combined treatment of high-risk DAVFs.

\section{Transarterial Embolization}

After thorough angiographic evaluation, the arterial inflow to the lesion is reduced by transarterial embolization using polyvinyl alcohol (PVA) foam particles. As many feeding arteries as possible arising from the dural branches of the ECA are selectively cannulated using microcatheters and then embolized. Selective cannulation of the posterior meningeal branch of the vertebral artery (VA) and the marginal tentorial branch of the ICA is attempted if the arteries are actively involved with the blood supply to the fistula and if they are hypertrophic. These branches are embolized using a 20 to $30 \%$ concentration of liquid embolic material, $N$-butyl-cyanoacrylate (NBCA), which is diluted and opacified by the oily contrast material (Lipiodol; Guerbet, Paris, France). Additionally, if large fistulas are found on the ECA branches, they are embolized with high-concentration (70\%) NBCA.

\section{Transvenous Embolization}

The pathological segment of the sinus is packed as tightly as possible with microcoils within a few days after transarterial embolization and before recanalization becomes prominent. If the DAVFs are associated with unifocal occlusion in the lateral sinus, placement of a microcatheter into the pathological segment of the sinus is attempted via a transfemoral approach. The diseased segment of the venous sinus is packed by placing thin, long platinum coils (0.018 in) such as Guglielmi detachable coils (GDCs) or interlocking detachable coils, (IDCs) (Boston Scientific Co., Natick, MA) and short, fibered coils such as Vortex coils (Boston Scientific Co.) or Tornado coils (Cook Inc., Bloomington, IN) alternatively. If the transfemoral approach to the diseased sinuses is not possible because of severe stenoses or bifocal occlusion of the sinus or if the fistula is not completely obliterated via a transfemoral approach, intraoperative embolization is performed. A craniectomy or a small burr hole enables direct access to the diseased segment of the venous sinus. The diseased segment of the dural sinus is directly packed with larger fibered occlusion coils ( 0.038 or $0.035 \mathrm{in})$, 
such as Gianturco coils (Cook Inc.), under the guidance of intraoperative digital subtraction angiography.

\section{Complementary Surgical Procedures}

Surgical isolation or resection of the diseased segment of the sinus is performed if a persistent fistula with LRVD is revealed on control angiography. These complementary surgical procedures are performed as follows: first, hypertrophic dural branches of the occipital artery are coagulated and cut off at their entry into the posterior aspect of the mastoid bone. After performing craniotomy and localized mastoidectomy, the transverse sinus and the upper part of the sigmoid sinus are exposed. A rete of markedly hypertrophic dural arteries, observed at the transverse-sigmoid junction, is coagulated. Two dural incisions are then made parallel to the long axis of the transverse sinus. By reflecting the dura mater that overlies the cerebellar hemisphere, the posterior meningeal branch of the VA, which is entering the fistula, is sought and coagulated. A dilated marginal tentorial artery, which is seen below the tentorium cerebelli, is sought and coagulated. When the lesion is located posteriorly, multiple dural branches that penetrate the skull through the honeycomb-like perforations are noted in the external occipital protuberance. After turning back the scalp flap, blood usually pours from these holes, but this can be prevented by performing transarterial embolization beforehand. A maze of dilated dural arteries, seen at the confluence of the sinuses, is coagulated. When inspecting the tentorium cerebelli from below, retrograde filling of the vermian veins is often noted. Connected directly, or indirectly via the tentorial sinus, to the transverse sinus or the confluence of sinuses, theses veins are first coagulated and then severed. The dura mater overlying the occipital lobe is then reflected. After elevating the occipital lobe, several cortical veins, including the vein of Labbé are recognized and are double ligated and divided. After severing the superior petrosal sinus, the pathological segment of the transverse and sigmoid sinuses is cut from the tentorium cerebelli and completely resected.

Surgical procedures are performed in patients after anesthesia is induced with isoflurane and supplemented with fentanyl. Neurophysiological monitoring is used only in patients who require test occlusion for cortical veins with ambivalent flow and in those whose venous sinuses are without occlusive changes. If prominent hyperemia and swelling of adjacent brain region are noted during surgery or on diagnostic imaging, these complementary surgical procedures are postponed for a few weeks.

We performed control angiography intraoperatively, 1 week, 3 months, 6 months, 1 year, and 2 years posttreatment. The DAVF was considered completely obliterated or eliminated when no early opacification of venous structures was demonstrated in the previous lesion site in immediate follow-up examination. When complete DAVF obliteration or elimination persisted and when regression of the feeding pedicles that come from the dural and pial arteries was observed at late follow-up examination ( $>1$ year), the lesion was defined as angiographically cured. Neurological evaluation was performed immediately pre- and posttreatment and at the time of follow-up angiography by a boardqualified neurologist. Clinical cure was defined as disappearance of the following: recurrent stroke, tinnitus, and signs and symptoms of focal cortical abnormality, generalized cerebral dysfunction, and increased ICP.

\section{RESULTS}

Using this treatment protocol, angiographically demonstrated complete cure of the DAVF was achieved in all cases, although three patients refused follow-up angiography after 6 months. In some initial cases with extremely high flow and extensive lesions, the angiographic follow-up period was extended more than 2 years. Clinical cure was attained in all patients, although neurological deficits persisted in seven: visual field defect and dysphasia caused by previous subcortical hemorrhage in five and slight dementia in two (Table 2). The clinical follow-up period was extended up to several years in some cases because of the persistence of subjective symptoms and/or neurological deficits. No treatment-related neurological deficit was seen in any case. 


\begin{tabular}{|c|c|c|c|c|c|c|c|c|c|c|}
\hline \multirow[b]{2}{*}{$\begin{array}{l}\text { Case } \\
\text { No. }\end{array}$} & \multirow[b]{2}{*}{$\begin{array}{l}\text { Age } \\
\text { (ys } \\
\text { Sex }\end{array}$} & \multirow[b]{2}{*}{$\begin{array}{l}\text { Site of } \\
\text { Lesion }\end{array}$} & \multirow[b]{2}{*}{$\begin{array}{l}\text { Symptorns } \\
\text { \& Imaging } \\
\text { Findings }\end{array}$} & \multirow[b]{2}{*}{$\begin{array}{c}\text { 1st } \\
\text { Treat- } \\
\text { mert }\end{array}$} & \multirow[b]{2}{*}{$\begin{array}{l}\mathrm{Re}- \\
\text { sult }\end{array}$} & \multirow[b]{2}{*}{$\begin{array}{l}\text { Treat- } \\
\text { mert } \\
\text { Interval }\end{array}$} & \multicolumn{2}{|c|}{ Final Treatment } & \multicolumn{2}{|c|}{$\begin{array}{l}\text { Last Follow } \\
\text { Up Result }\end{array}$} \\
\hline & & & & & & & $\begin{array}{l}\text { Endo- } \\
\text { vascuar } \\
\text { Approach }\end{array}$ & Sugical & $\begin{array}{l}\text { Angio- } \\
\text { graphic }\end{array}$ & $\begin{array}{l}\text { Neuro } \\
\text { logical }\end{array}$ \\
\hline 1 & 28, M & It TS & $\begin{array}{l}\text { Gerstmann } \\
\text { Syndrome } \\
\text { suboorthem }\end{array}$ & & & & $\begin{array}{c}\text { transart + } \\
\text { transiven }\end{array}$ & resection & $\begin{array}{l}\text { cure } \\
(6 \text { yrs) }\end{array}$ & $\begin{array}{l}\text { in tact } \\
\text { (6 yrs) }\end{array}$ \\
\hline$\dagger 2$ & 34, M & $\begin{array}{l}\text { rt TS (si- } \\
\text { nus (wall) }\end{array}$ & $\begin{array}{l}\text { hemianopsia, } \\
\text { suboort hem }\end{array}$ & & & & transart & $\begin{array}{r}\text { disconnect } \\
\text { the LRVD }\end{array}$ & $\begin{array}{l}\text { cure } \\
\text { (2 yrs) }\end{array}$ & $\begin{array}{l}\text { quadra- } \\
\text { nopia } \\
\text { (3 ins) }\end{array}$ \\
\hline$\dagger 3$ & $45, M$ & $\begin{array}{l}\text { rt TS (si- } \\
\text { nus inal) }\end{array}$ & $\begin{array}{l}\text { coma, sub- } \\
\text { dural, \& sub } \\
\text { cort hem }\end{array}$ & & & & transart & $\begin{array}{r}\text { disconnect } \\
\text { the LRVD }\end{array}$ & $\begin{array}{l}\text { cure } \\
\text { (2 yrs) }\end{array}$ & $\begin{array}{l}\text { hemi- } \\
\text { anopia } \\
\text { (3 yrs) }\end{array}$ \\
\hline 4 & $62, M$ & $\begin{array}{l}\text { It TSS (S. } \\
\text { ocdud- } \\
\text { ed }\end{array}$ & $\begin{array}{l}\text { headache, } \\
\text { tinnitus, ce- } \\
\text { retral infarct }\end{array}$ & $\begin{array}{l}\text { ligation } \\
\text { of } C \mathrm{C} A+ \\
\text { irradition }\end{array}$ & $\mathrm{RC}$ & 4 yrs & $\begin{array}{c}\text { transart + } \\
\text { transwen }\end{array}$ & resection & $\begin{array}{l}\text { cure } \\
\text { (6 mos) }\end{array}$ & $\begin{array}{l}\text { in tact } \\
(6 \text { yrs) }\end{array}$ \\
\hline 5 & $51, M$ & $\begin{array}{l}\text { It TSS (S. } \\
\text { ocdud- } \\
\text { ed }\end{array}$ & $\begin{array}{l}\text { headache, apha- } \\
\text { sia, SAH, } \\
\text { suboort hem }\end{array}$ & $\begin{array}{l}\text { transart } \\
\text { embol }\end{array}$ & $\mathrm{RC}$ & $6 \mathrm{mos}$ & $\begin{array}{c}\text { transart + } \\
\text { transwen }\end{array}$ & resection & $\begin{array}{l}\text { cure } \\
\text { (2yrs) }\end{array}$ & $\begin{array}{l}\text { dyspha- } \\
\text { sia (3 } \\
\text { yts) }\end{array}$ \\
\hline 6 & $62, F$ & $\begin{array}{l}\text { It TSS } \\
\text { (isolated) }\end{array}$ & $\begin{array}{l}\text { seizure, dif- } \\
\text { fuse train } \\
\text { swelling }\end{array}$ & & & & transart & $\begin{array}{l}\text { intraop } \\
\text { embol }\end{array}$ & $\begin{array}{l}\text { cure } \\
\text { (1 yr) }\end{array}$ & $\begin{array}{l}\text { in tact } \\
\left(1 y^{\prime}\right)\end{array}$ \\
\hline 7 & $64, F$ & $\begin{array}{l}\text { It TSS } \\
\text { (isolated) }\end{array}$ & $\begin{array}{l}\text { mental de- } \\
\text { terioration, } \\
\text { diffuse train } \\
\text { suelling }\end{array}$ & & & & transart & $\begin{array}{l}\text { intrao } p \\
\text { embol }\end{array}$ & $\begin{array}{l}\text { cure } \\
\text { (2 yrs) }\end{array}$ & $\begin{array}{l}\text { intact } \\
\text { (8 yrs) }\end{array}$ \\
\hline 8 & $62, M$ & $\begin{array}{l}\text { It TSS } \\
\text { (isolated) }\end{array}$ & $\begin{array}{l}\text { mental de- } \\
\text { terioration, } \\
\text { diffuse train } \\
\text { suelling }\end{array}$ & & & & transart & $\begin{array}{l}\text { intraop } \\
\text { embol }\end{array}$ & $\begin{array}{l}\text { cure } \\
\text { (2 yrs) }\end{array}$ & $\begin{array}{l}\text { intact } \\
\text { (4 yrs) }\end{array}$ \\
\hline 9 & $66, M$ & $\begin{array}{l}\text { It TSS } \\
\text { (isolated) }\end{array}$ & $\begin{array}{l}\text { hemianopsia, } \\
\text { suboorthem }\end{array}$ & $\begin{array}{l}\text { transart } \\
\text { embol }\end{array}$ & $\mathrm{RC}$ & $2 \mathrm{mos}$ & transart & $\begin{array}{l}\text { intraop } \\
\text { embol }\end{array}$ & $\begin{array}{l}\text { cure } \\
\text { (6 mos) }\end{array}$ & $\begin{array}{l}\text { hemi- } \\
\text { anopia } \\
\text { (5 ins) }\end{array}$ \\
\hline 10 & $49, F$ & $\begin{array}{l}\text { It TSS } \\
\text { (isolated) }\end{array}$ & $\begin{array}{l}\text { hemianopsia, } \\
\text { suboorthem }\end{array}$ & $\begin{array}{l}\text { transart } \\
\text { embol }\end{array}$ & $\mathrm{RC}$ & 3 yrs & transart & $\begin{array}{l}\text { intraop } \\
\text { embol }\end{array}$ & $\begin{array}{l}\text { cure } \\
\text { (2 yrs) }\end{array}$ & $\begin{array}{l}\text { hemi- } \\
\text { anopia } \\
\text { (8 yrs) }\end{array}$ \\
\hline 11 & $42, F$ & $\begin{array}{l}\text { It TSS } \\
\text { (isolated) }\end{array}$ & $\begin{array}{l}\text { easily fatiged, } \\
\text { headache, } \\
\text { SAH }\end{array}$ & $\begin{array}{l}\text { transart } \\
\text { embol + } \\
\text { ECA li- } \\
\text { gation }\end{array}$ & $\mathrm{RC}$ & 2 yrs & transart & $\begin{array}{l}\text { intraop } \\
\text { embol + } \\
\text { isolation }\end{array}$ & $\begin{array}{l}\text { cure } \\
\text { (2 yrs) }\end{array}$ & $\begin{array}{c}\text { intact } \\
\text { (6 yrs) }\end{array}$ \\
\hline 12 & $36, M$ & $\begin{array}{l}\text { rt TSS } \\
\text { (isolated) }\end{array}$ & $\begin{array}{l}\text { exophthalmos, } \\
\text { cerebral in- } \\
\text { farct }\end{array}$ & & & & transart & $\begin{array}{l}\text { intraop } \\
\text { embol + } \\
\text { isolation; } \\
\text { resection }\end{array}$ & $\begin{array}{l}\text { cure } \\
\text { (1 yr) }\end{array}$ & $\begin{array}{l}\text { intact } \\
\text { (4 yrs) }\end{array}$ \\
\hline 13 & $61, M$ & $\begin{array}{l}\text { It TSS } \\
\text { (isolated) }\end{array}$ & $\begin{array}{l}\text { headache, dif- } \\
\text { fuse brain } \\
\text { swelling }\end{array}$ & & & & transart & $\begin{array}{l}\text { intraop } \\
\text { embol re- } \\
\text { section }\end{array}$ & $\begin{array}{l}\text { cure } \\
\text { (2 yrs) }\end{array}$ & $\begin{array}{l}\text { intact } \\
\text { (3 yrs) }\end{array}$ \\
\hline
\end{tabular}




\begin{tabular}{|c|c|c|c|c|c|c|c|c|c|c|}
\hline 14 & $58, M$ & $\begin{array}{r}\text { It TSS } \\
\& \mathrm{CS}\end{array}$ & $\begin{array}{l}\text { Gerstmann } \\
\text { Syndrome, } \\
\text { cerebral in- } \\
\text { farct }\end{array}$ & & & & transart & $\begin{array}{l}\text { intraop } \\
\text { embol + } \\
\text { resection } \\
\text { of It TSS } \\
\& \text { It half of } \\
\text { CS }\end{array}$ & $\begin{array}{l}\text { cure } \\
\text { (2 yrs) }\end{array}$ & $\begin{array}{c}\text { in tact } \\
(5 \mathrm{yr} s)\end{array}$ \\
\hline 15 & 42 , M & tilat TSS & $\begin{array}{l}\text { seizure, apha- } \\
\text { sia, ceretral } \\
\text { infarct }\end{array}$ & $\begin{array}{l}\text { transart } \\
\text { embol }\end{array}$ & $\mathrm{RC}$ & $10 \mathrm{mos}$ & transart & $\begin{array}{l}\text { intraop } \\
\text { em bol of } \\
\text { It TSS, } \\
\text { isolation } \\
\text { of it TSS }\end{array}$ & $\begin{array}{l}\text { cure } \\
\text { (2 yrs) }\end{array}$ & $\begin{array}{l}\text { in tact } \\
\text { (2 yrs) }\end{array}$ \\
\hline 16 & $59, M$ & $\begin{array}{c}\text { tilat TSS } \\
\& \mathrm{CS}\end{array}$ & $\begin{array}{l}\text { mental de te- } \\
\text { rioration, } \\
\text { suboorthem }\end{array}$ & $\begin{array}{l}\text { transart } \\
\text { embol }\end{array}$ & $\mathrm{RC}$ & $3 \mathrm{mos}$ & $\begin{array}{c}\text { transart + } \\
\text { transwen }\end{array}$ & $\begin{array}{l}\text { in traop } \\
\text { embol + } \\
\text { isolation, } \\
\text { resection } \\
\text { of tilat } \\
\text { TSS \& CS }\end{array}$ & $\begin{array}{l}\text { cure } \\
\text { (6 mos) }\end{array}$ & $\begin{array}{l}\text { slight } \\
\text { demen- } \\
\text { ta (5 } \\
\text { yrs) }\end{array}$ \\
\hline$\ddagger 17$ & $62, F$ & $\begin{array}{l}\text { tilat TSS } \\
\& \mathrm{CS}\end{array}$ & $\begin{array}{l}\text { mental de te- } \\
\text { rioration, } \\
\text { headache, } \\
\text { SAH }\end{array}$ & $\begin{array}{c}\text { transart } \\
\text { embol }\end{array}$ & $\mathrm{RC}$ & $3 \mathrm{mks}$ & transart & $\begin{array}{l}\text { isolation of } \\
\text { tilat TSS } \\
\text { \& CS }\end{array}$ & $\begin{array}{l}\text { cure } \\
\text { (2 yrs) }\end{array}$ & $\begin{array}{l}\text { slight } \\
\text { demen- } \\
\text { ta (8 } \\
\text { yss) }\end{array}$ \\
\hline \multicolumn{11}{|c|}{ 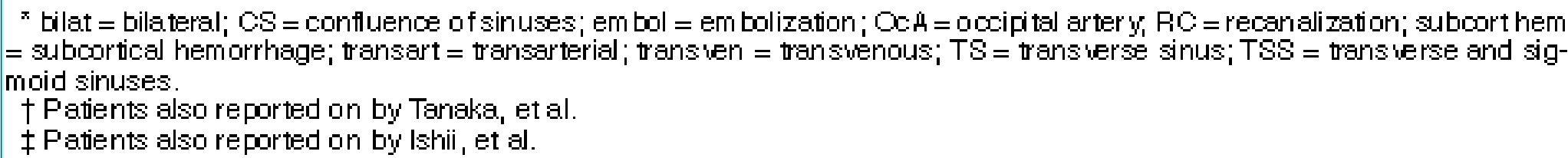 } \\
\hline
\end{tabular}

Of 13 patients with unilateral DAVF of the transverse and sigmoid sinuses, in three, preoperative transfemoral transvenous embolizations were possible; the patent in Case 1 was the only patient who did not have occlusive change of the dural sinus or LRVD (Fig. 1). This patient had extremely abundant arterial flow to the fistula from the dural and pial arteries (Fig. 1). After surgical resection of the diseased segment of the sinus, a complete cure was attained. This became possible by the regression of engorgement of pial arteries brought about by the transfemoral transvenous embolization of the sinus. In the other two patients (Cases 4 and 5), the sigmoid sinus that carried the DAVF was occluded before its junction with the jugular bulb. Therefore, a microcatheter was advanced into the diseased segment of the lateral sinus, down to the occlusion site in the sigmoid sinus via the confluence of sinuses, and into the contralateral transverse sinus via a transfemoral approach. Most of the diseased segment of the lateral sinus was embolized, but the fistula was not completely occluded and LRVD persisted. Surgical resection of the entire diseased segment was easily achieved because marked reduction of blood flow through the fistula had been attained by performing preoperative embolization. 


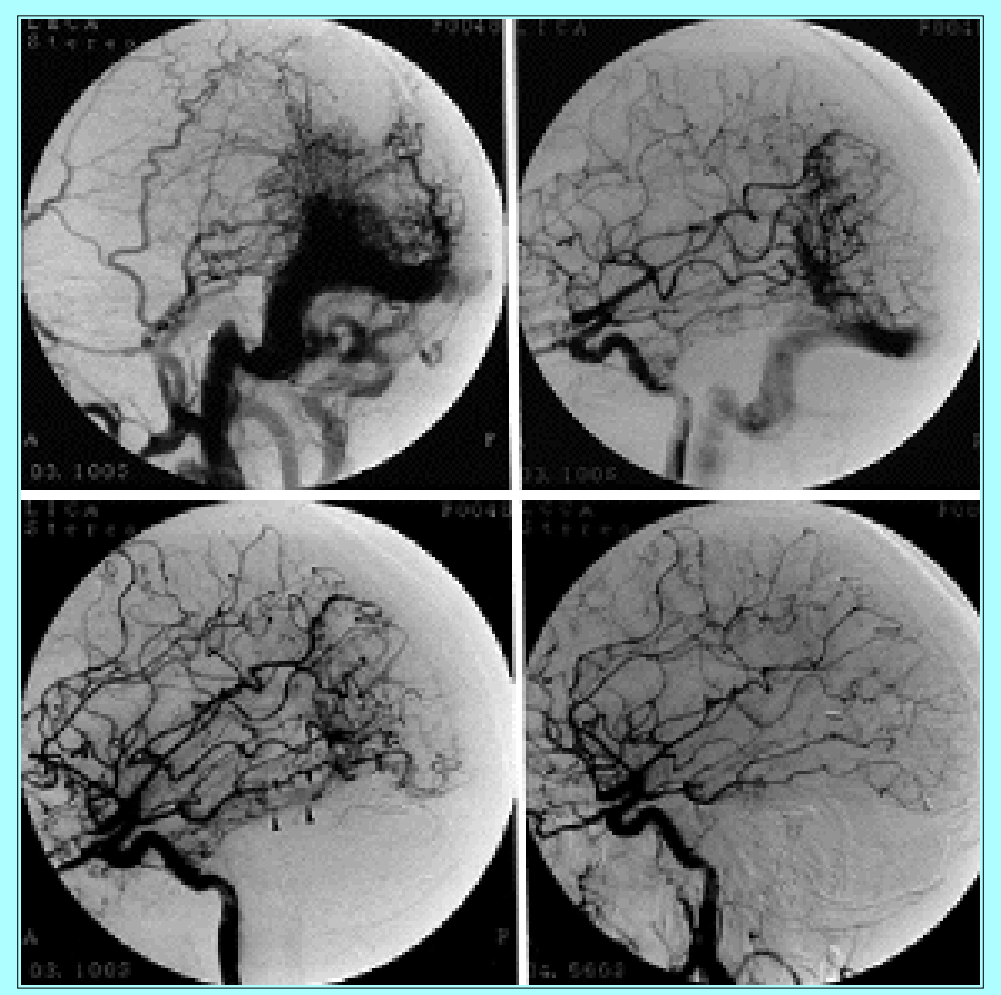

Fig. 1. Case 1. Angiographic study. Upper Left: Left ECA angiogram, lateral view, demonstrating an extremely high flow DAVF of the transverse sinus that drains in the ante- and retrograde fashion. Note markedly dilated numerous dural arteries converged on the fistula. No definite LRVD was observed. Upper Right: Left ICA angiogram, lateral view, showing a prominent dilation of numerous leptomeningeal arteries of the cortical middle cerebral artery branches converging on the fistula. Lower Left: Left ICA angiogram, obtained 1 week after transfemoral transvenous embolization of the transverse sinus. Note a marked regression of the pial supply to the DAVF compared with image in upper right. There is no opacification of the lateral sinus; instead, there is an increased prominence of the draining of the fistula into the tentorial sinus (arrowheads). Lower Right: Control left common carotid artery angiogram, obtained 1 week after resection of the diseased segment of the transverse sinus, showing complete disappearance of the DAVF. Note prominent regression of size of previously hypertrophic middle cerebral artery and ECA branches.

In two patients (Cases 2 and 3), the fistula was localized on the sinus wall and drained predominantly into the cortical veins that carried varices (reported elsewhere [35]). Following transarterial embolization, a small craniotomy was performed, and the arterial inflow was coagulated. The disease was cured by surgically disconnecting the cortical veins at the point of their exit from the fistula and the dural sinus, taking care not to sacrifice the patency of the dural sinus.

In eight patients (Cases 6-13), the diseased segment of the lateral sinus was completely isolated from the other venous sinuses by bifocal occlusions of the sinus and associated with prominent LRVD (Fig. 2). 


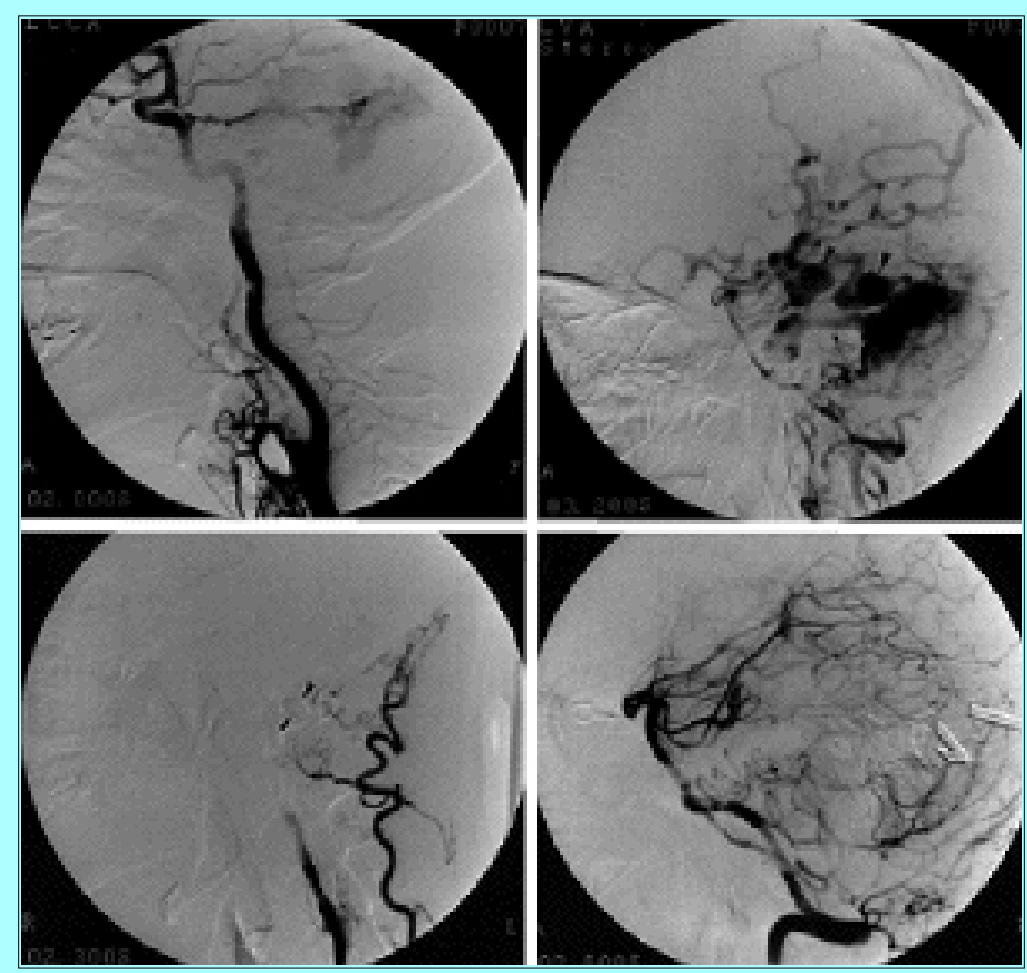

Fig. 2. Case 11. Angiographic study. Upper Left: Left common carotid artery angiogram, lateral view, showing the ECA trunk, which was ligated at an outside hospital, and the hypertrophic marginal tentorial artery of the ICA. Upper Right: Left subclavian angiogram, lateral view, showing reconstitution of the occipital artery via the ascending and deep cervical arteries. The dural branches of the VB system were the main feeding pedicles of the fistula. Note the prominent LRVD from the isolated transverse sinus via the dilated vein of Labbé and the superior petrosal sinus. There were varices on the vein of Labbé and the lateral mesencephalic vein (arrowheads). Lower Left: Left subclavian angiogram, lateral view, demonstrating marked reduction of blood flow to the DAVF after embolization of muscular branches of the VA and the ascending and deep cervical arteries by using PVA particles. Embolization was performed following occlusion of the left VA at the level of the vertebral groove with a detachable balloon (arrowheads). Lower Right: Control right VA angiokl;dsgram, obtained 1 week after intraoperative embolization, confirming complete occlusion of the DAVF.

On angiography, five were completely obliterated by performing intraoperative embolization alone. For the other three cases with DAVF that widely involved the lateral sinuses, complementary surgical procedures (Cases 11 and 12) or combined surgery and radiotherapy (30 Gy) (Case 13) were necessary to achieve complete obliteration. Following intraoperative embolization, blood supply from the feeding pedicles, which had been inaccessible by the transfemoral transarterial embolization, gradually declined. In the remaining four patients (Cases 14-17), large areas in the bilateral cerebral hemispheres were exposed to venous hypertension because of the involvement of the confluence of sinuses and/or the bilateral lateral sinuses (Figs. 3 and 4). 


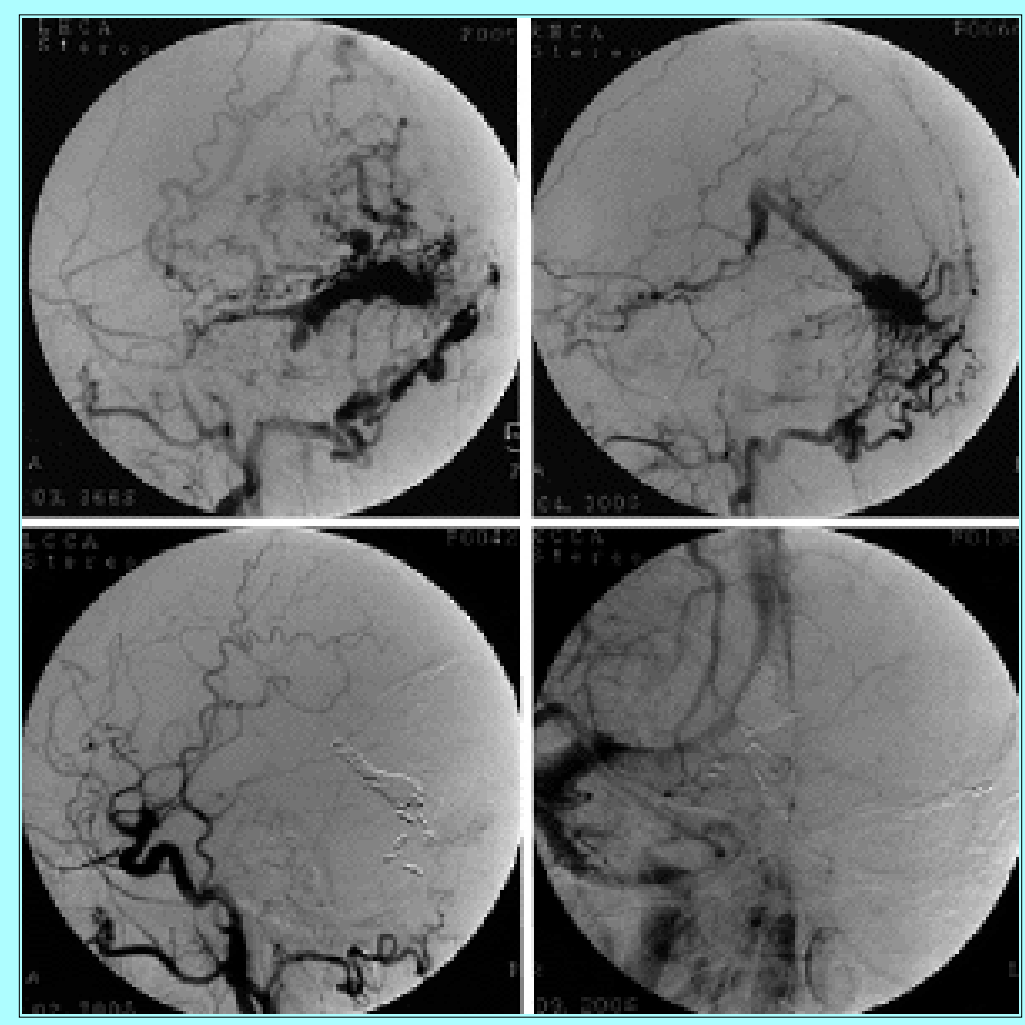

Fig. 3. Case 14. Angiographic study. Upper Left: Left ECA angiogram, lateral view, showing a high-flow DAVF of the isolated lateral sinus by bifocal occlusion, which features prominent LRVD. Upper Right: Right ECA angiogram, lateral view, revealing a DAVF of the confluence of sinuses with prominent reflux into the straight sinus and its tributaries. Lower Left: Control left common carotid artery angiogram, obtained 1 week postsurgery, showing complete elimination of the DAVF. Note the coils that pack the left half of the confluence of sinuses and superior petrosal and sigmoid sinuses, which were left in place. Lower Right: Venous phase of right ICA angiogram, anteroposterior view, confirming preservation of normal antegrade flow from the sagittal to the right transverse sinuses. Note the coils that pack the left half of the confluence of sinuses and parts of the superior petrosal and the sigmoid sinuses, which were left in place.

Treating this area of the vascular anatomy was complicated because the lateral sinus was largely occluded or isolated from the rest of the venous sinuses and was associated with prominent LRVD. In addition, arterial blood supply was problematic, because the diseased segment of the dural sinus received numerous feeding pedicles coming from bilateral extra- and intracranial circulation. The patient in Case 14 had undergone intraoperative embolization of the isolated segments of the sinuses. These sinuses were then resected to eliminate the lesion completely. In the patient in Case 15, the DAVF of the segregated left lateral sinus was obliterated by intraoperative embolization, and the DAVF of the contralateral transverse sinus was obliterated after surgical isolation and irradiation $(30 \mathrm{~Gy})$; this maintained the patency of the sinus, which acted as a major route out of intracranial circulation. In the patient in Case 16, who had extremely well developed bilateral sphenoparietal sinuses, we performed intraoperative embolization on the bilateral transverse and sigmoid sinuses and the confluence of sinuses followed by resection of these sinuses. Postoperative transfemoral embolization of the residual fistula in the right sigmoid and the superior petrosal sinus resulted in angiographically demonstrated complete cure. In the patient in Case 17, after we performed an extensive transarterial embolization of the dural branches of the bilateral ECA, only the surgical isolation of the spontaneously obliterated bilateral lateral sinuses and the confluence of sinuses resulted in angiographic cure (reported elsewhere [19]). There was no incidence of profuse bleeding during skin incision and bone removal because of the presurgical transarterial embolization, and blood transfusion was not necessary in any of the 


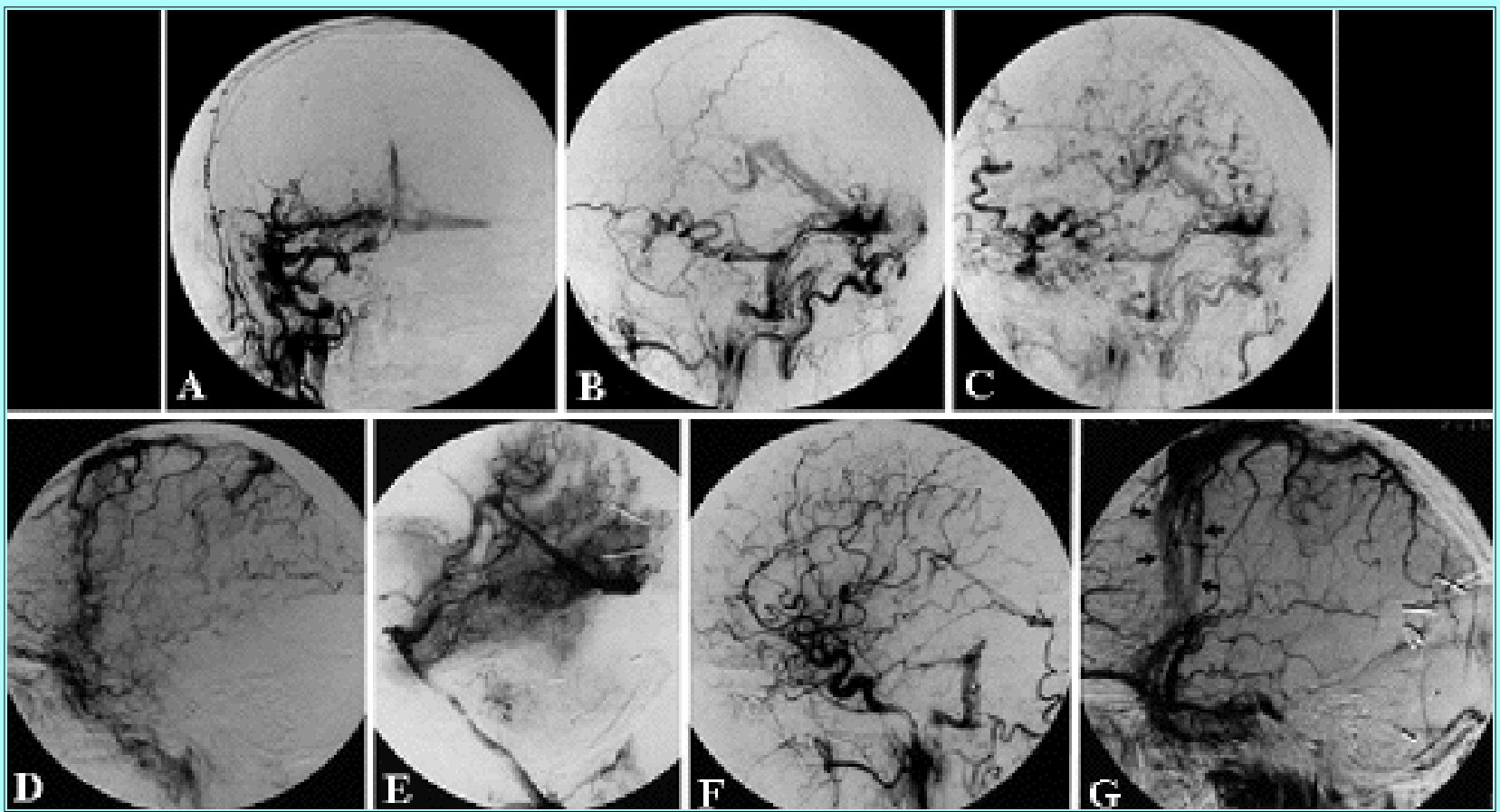

Fig. 4. Case 16. Angiographic study. Right ECA angiograms, anteroposterior (A) and lateral (B) views, showing an extensive DAVF that involves the bilateral lateral sinuses and the confluence of sinuses. The medial part of bilateral transverse sinus is segregated from the other venous sinuses due to occlusion of the left transverse and sigmoid sinuses and the posterior part of the superior sagittal sinus. The lateral half of the right transverse sinus is severely stenotic. Reflux into the straight sinus, superior petrosal sinus, and their tributaries is prominent. A right ECA angiogram (C), lateral view, in the venous phase, showing prominent retrograde filling of the dilated cortical veins in the posterior half of the right cerebral hemisphere. A right ICA angiogram (D), lateral view, in the venous phase, showing congestion of the cortical veins in the posterior two thirds of the cerebral hemisphere. Major runoff of the superior sagittal sinus was established through the hypertrophic bilateral sphenoparietal sinuses, which were faintly opacified (arrows). These sinuses further enlarged postsurgery and later densely opacified (see Fig. 4H). Control arterial phase VA angiogram (E), lateral view, 1 month after surgical devascularization of the bilateral transverse sinuses and the confluence of sinuses. Note prominent filling of the straight sinus via leptomeningeal arteries of the bilateral PCA and superior cerebellar artery. Control venous phase left common carotid artery angiogram (F), lateral view, obtained at the same time as the image in Fig. 4G. Note persistent filling of the sigmoid, superior petrosal, and the straight sinuses. Control venous phase left common carotid artery angiogram $(\mathrm{G})$ obtained 3 months after resection of the sinuses. Note disappearence of the cortical venous congestion and reconstitution of the venous outflow via bilaterally hypertrophic sphenoparietal sinuses (arrows).

\section{ILLUSTRATIVE CASES}

\section{Case 1}

History and Examination. This 28 -year-old man was originally diagnosed as having a DAVF in the left transverse-sigmoid junction at the age of 4 years, when he displayed symptoms that included left conjunctival injection and proptosis. At age 19 years he suddenly developed severe headache, right-sided hemiplegia, and disturbance of consciousness. He was admitted to a nearby hospital and was found to have a large subcortical 
hematoma that involved the left temporal and parietal lobes. Evacuation of the hematoma was performed, and the DAVF was left untouched. After recovering from this acute episode, the patient suffered from recurrent episodes of seizure, syncopal attack, and transient Gerstmann syndrome. Angiography demonstrated one unique feature in this patient; there was prominent participation of numerous pial arteries with the DAVF in addition to the ECA branches (Fig. 1 upper left and right).

Operation. Initially, transarterial embolization was performed. The tip of the microcatheter was advanced deep into the ECA branches close to the fistula where three main feeding pedicles that carried relatively large fistulas were embolized using a small amount of diluted (30\%) NBCA. The left ECA branches were then extensively embolized using PVA particles. Four days later, via the transfemoral approach, the pathological segment of the sinus was tightly packed with platinum coils. One day after embolization, a small subcortical hematoma, located lateral to the atrium of the left lateral ventricle, was revealed by computerized tomography scanning; however, the patient remained neurologically intact. One week after embolization, a control angiogram demonstrated a marked subsidence of the pial artery engorgement; however, the DAVF was not completely obliterated by embolization, and a fistula between the pial vessels and the tentorial sinus became prominent (Fig. 1 lower left). The pathological segment of the dural sinus, which extended from the confluence of sinuses to the superior petrosal sinus, was resected. The sinus was severely adherent to the temporal lobe in the transverse-sigmoid junction, where numerous leptomeningeal arteries converged in the fistula. There was no profuse bleeding during surgery. A control angiogram showed complete disappearance of the DAVF (Fig. 1 lower right). The number of seizures has dramatically decreased, and the patient has been neurologically intact for the past 6 years.

\section{Case 11}

History and Examination. This 42-year-old woman who had previously undergone embolization and ligation of the ECA for a DAVF of the left transverse and sigmoid sinuses at another hospital (Fig. 2 upper left) suffered a subarachnoid hemorrhage (SAH) 2 years later. Preembolization angiography revealed a recurrent DAVF that was characterized by numerous feeding pedicles that were reconstituted by collateral branches, a transverse sinus isolated by bifocal sinus occlusion, and prominent LRVD (Fig. 2 upper right).

Operation. After the patient underwent endovascular occlusion of the left VA by using a detachable balloon placed at the distal $\mathrm{C}_{1}$ segment, muscular branches of the VA and branches of the deep and ascending cervical arteries were extensively embolized with PVA particles (Fig. 2 lower left). A left occipital and suboccipital craniotomy was performed 3 days later to expose the transverse and sigmoid sinuses. After coagulating the posterior branch of the middle meningeal artery and the dural branches of the posterior cerebral artery (PCA), a microcatheter was placed directly into the isolated segment of the transverse and sigmoid sinuses. This diseased segment was packed tightly with occlusion coils (mostly Gianturco coils and supplemented by IDCs and Vortex coils) and was surgically isolated from the adjacent dura mater. It was noted, however, that a varicose vein, which was found on the vein of Labbé at its entry to the sinus, remained reddish. After inspecting the inner aspect of the varix, a small arterial twig that arose from the PCA was connected to the varix. This twig was coagulated, and finally the varix collapsed. Complete obliteration of the DAVF was confirmed by immediate (Fig. 2 lower right) and late follow-up angiography. The patient has been neurologically intact for the past 6 years, during which time she has not experienced headache or been easily fatigued.

\section{Case 14}

Examination. This 58-year-old man suffered from Gerstmann syndrome caused by a venous infarct of the temporal lobe. Angiographic examination revealed an extensive DAVF that extended from the left sigmoid to the confluence of sinuses (Fig. 3 upper left and right). The bilateral ECA branches were extensively 
embolized using PVA particles, and the posterior meningeal branches of the left VA were embolized using NBCA. Surgery was performed the following day. The soft tissue and the bone did not bleed more than usual due to the effect of embolization. After coagulating many dural and tentorial branches, the segregated transverse sinus, the left half of the confluence of sinuses, and the straight sinus were tightly packed with microcoils. However, the transverse sinus contained a few different channels, not all of which were obliterated. Control angiography revealed disappearance of reflux into most of the cortical veins and the deep venous system. However, there were several cortical veins, including the duplicated veins of Labbé, which were still draining arterialized blood. After confirming the subsidence of hyperemia of the left occipital lobe and left cerebellar hemisphere, surgery was performed. All tentorial arteries and cortical veins were disconnected, and the transverse sinus was resected. Control angiography revealed complete elimination of the DAVF (Fig. 3 lower left). The flow from the superior sagittal sinus to the right transverse sinus was completely preserved (Fig. 3 lower right). The patient has been neurologically intact for the past 5 years.

\section{Case 16}

History. This 59-year-old man developed tinnitus in his right ear approximately 10 years ago and since then has had occasional episodes of SAH, headache, and vomiting. He gradually developed gait disturbance, hallucinations, and urinary incontinence approximately 1 year prior to admission to a nearby university hospital. He developed a subcortical hematoma in the right occipital lobe several hours after the angiography. Transarterial embolization, performed twice at the same hospital, only transiently reduced the degree of tinnitus.

The patient was referred to us, and angiography performed at our institute showed an extensive DAVF that involved the bilateral lateral sinuses and the confluence of sinuses (Fig. 4A). The medial part of the bilateral transverse sinuses was segregated from the rest of the venous sinuses because of an extensive occlusive process. Reflux of shunted blood into the straight sinus, the superior petrosal sinus, and their tributaries was prominent (Fig. 4B). A diffuse congestion of dilated cortical veins was noted in the posterior two thirds of the bilateral cerebral hemispheres (Fig. 4C). It was also noted that major venous run off of cerebral venous circulation was established through hypertrophic bilateral sphenoparietal sinuses (arrows in Fig. 4D). Therefore, it was expected that the patient would tolerate surgical isolation of the pathological segment of the sinuses. After embolization using PVA particles of the dural branches of the bilateral ECA and the VA, an extensive horseshoe-shaped skin incision was made that extended from the nuchal midline portion to the bilateral retroauricular regions. Bleeding during skin incision was no more than usual. A bilateral occipital and suboccipital craniotomy over the lateral sinuses and the confluence of sinuses was performed. Localized mastoidectomies were then performed bilaterally to expose the transverse-sigmoid junction. The rete of dilated dural branches, which was most prominent in the transverse-sigmoid junction and the confluence of sinuses, was thoroughly coagulated. After severing the dura mater above and below the transverse sinus, the tentorial arteries were coagulated extensively from below and above the tentorium cerebelli. The occipital and the superior sagittal sinuses were clipped and severed. However, cortical veins connected to both supraand infratentorial structures and the straight sinus were left untouched so as not to compromise the venous circulation further. The dura mater on both sides of the sinus was resected (width $1 \mathrm{~cm}$ ) and replaced with artificial dura to prevent revascularization of the fistula. The postoperative course was uneventful. However, control vertebral angiography, performed 1 month after the procedure, showed prominent filling of the straight sinus via the leptomeningeal arteries of the bilateral PCA and the superior cerebellar artery, which was not seen preoperatively (Fig. 4E) Also, control left common carotid artery angiography revealed persistent filling of the sigmoid, superior petrosal, and the straight sinuses via the remaining tentorial branches (Fig. 4F).

Second Operation. At second surgery, no area with cerebral infarct was observed. Every cortical vein 
connected to the bilateral transverse sinuses and the confluence of sinuses was resected infra- and supratentorially. The straight sinus was then clipped and severed, and the medial halves of the bilateral transverse sinuses were resected, including the confluence of sinuses. No brain swelling was noted postprocedure. The residual DAVF at the transverse-sigmoid junction was embolized via a transfemoral-transvenous approach. Control angiography showed complete obliteration of the DAVF, disappearence of the cortical venous congestion, and reconstitution of the venous outflow via bilaterally hypertrophic sphenoparietal sinuses (Fig. 4G). Signs and symptoms of increased intracranial pressure quickly disappeared, and the patient slowly recovered from dementia over the years.

\section{DISCUSSION}

\section{Angiographic and Clinical Cure}

The final procedures in this systemic approach, which allowed us to cure, clinically and angiographically, 18 lesions in our 17 patients were as follows: intraoperative venous sinus embolization in five patients, surgical disconnection of LRVD in two, surgical isolation in four, and surgical resection in seven patients. In the past the only way to attain complete cure of a DAVF had been surgical removal of the lesion when catheterization techniques and embolic materials were premature. Recently, however, it was demonstrated that complete obliteration of the lesion became possible by tightly packing the diseased segment of the dural sinus with coils.[16,33,37] Because few histopathological studies of DAVF have been reported,[13,27] we have examined resected specimens obtained in nine of these cases.[17] We found an abnormal connection between the dural arteries and the dural veins within the venous sinus wall, through small vessels averaging approximately $30 \mu \mathrm{m}$ in diameter. Therefore, it seems possible that by densely packing the diseased segment of the sinus, firm thrombus is formed and that organized thrombus will then lead to permanent occlusion of the DAVF. Since the advent of long platinum coils such as GDCs and IDCs, dense packing of the sinus through microcatheters has become easy; however, use of only these platinum coils often leads to early recanalization of the lesion, despite dense packing, because these bare platinum coils are less thrombogenic. By weaving fibered coils into the mesh of the long platinum coils, formation of firm thrombus is facilitated. In our experience treating 85 patients with DAVFs in various sites, who underwent embolization of the diseased segment of venous sinuses, three of eight patients who underwent embolization with only IDCs experienced recanalization within 6 months. No angiogram demonstrated recurrence in later follow up when a complete angiographic obliteration had been observed at 6 months postprocedure.

\section{Angiographic Subtypes of High-Risk DAVFs}

The treatment strategy of DAVF should be decided mainly based on its angioarchitecture. Angiographically, the DAVFs in the 17 cases presented here are grouped into the following three types.

Extremely High-Flow DAVF Without Sinus Occlusion and LRVD. Functional obstruction of the sinus was postulated as a pathomechanism of focal cortical abnormality and SAH in Case 9. Resection of the diseased sinus segment completely cured this patient. Cure was achieved after the subsidence of hyperemia of the adjacent brain region, which was brought about by transvenous embolization of the fistulous portion of the dural sinus, but there was formation of a small subcortical hematoma, although asymptomatic, after the procedure. The necessity of performing a sinus occlusion test has been stressed for patients with DAVF with ambivalent flow in cortical veins.[33,37] However, the reliability and value of the occlusion test are doubtful; temporary occlusion is not predictive of the long-term effect, and additionally, no balloon is long enough to cover extensive lesions entirely. Furthermore, abrupt elevation of venous sinus pressure generated by occlusion test may induce intracranial hemorrhage and cerebral venous infarct. A combination of surgically isolating the diseased sinus segment followed by irradiation, as was performed after transarterial embolization in Case 15, is the treatment of choice for DAVFs located in sinuses that function as major 
runoff from cerebral venous circulation.

Localized DAVF With Exclusive LRVD. The fistulas were easily cured by a simple surgical disconnection of cortical veins from the sinus wall, with preservation of dural sinus patency in Cases 2 and 3; these results were similar to cases reported by Barnwell, et al.[3] Recently, Davies and coworkers[10] claimed that all cases that showed retrograde leptomeningeal drainage could be cured safely and effectively or converted to a benign type by eliminating only the retrograde leptomeningeal drainage, either by embolization or surgical disconnection, rather than surgical resection. The authors validated the classification and the treatment method of DAVFs proposed by Borden, et al.,[4] which dealt with arteriovenous shunts that were fed by the cranial and spinal dural arteries under the same category. However, this classification is unacceptable from the anatomical point of view.[22] Furthermore, we concur with Collice, et al.,[7] who claimed that only DAVFs with pure leptomeningeal drainage, which are confined to the wall of the dural sinus (as in our Cases 2 and 3), can be treated by the simple surgical interruption of a draining vein at its exit from the sinus wall; this has been performed successfully in DAVFs of tentorial sinus.[14,36] In the literature, DAVFs with pure leptomeningeal drainage are most commonly seen outside the major venous sinus, such as in the anterior fossa, the tentorial sinus, and the superior petrosal sinus.[2,4,30] Most of the DAVFs that are occasionally seen in the transverse and superior longitudinal sinuses seem to be "extrasinusal dural lesions,"[31] which develop in the transdural portion of the cerebral vein. In fact, not a single case of DAVF with pure leptomeningeal drainage that arose from the lateral sinus was found in the series by Borden, et al., but curiously, they used an illustration of DAVF of the transverse sinus to explain their new classification system of DAVFs. In addition, with regard to the general concept of DAVFs of the transverse sinus, their illustration was misleading for two reasons: 1) it gave the impression that all DAVFs with pure leptomeningeal drainage are generated under the process of recanalization of sinus thrombosis and 2) it oversimplified the angioarchitecture of the transverse sinus. Anatomical studies have been undertaken that demonstrate that the transverse sinus receives many cortical veins from the supra- and infratentorial structures, via capacious tentorial sinuses or directly, and often separately, into the sinus, as well as being connected to the emissary veins and the superior petrosal sinus.[25,26,29] Therefore, the following possibility must be kept in mind: clipping a leptomeningeal vein that drains the fistula after insufficient embolization results in rerouting the fistulous output and overloading other leptomeningeal veins.[30] Furthermore, from a technical point of view, it is important to recognize that even the clipping of a draining vein can be hazardous and might be responsible for a venous infarct and a fatal hemorrhage.[7] Therefore, some adjunctive measures should be undertaken to decrease the arteriovenous shunt progressively, the degree of venous engorgement, and the size of the venous bed recruited by the fistula.[21,30]

DAVF With Bifocal or Diffuse Sinus Occlusion and LRVD. All of the remaining 14 patients had LRVD-associated DAVFs, which extensively involved the lateral sinuses. They were associated with monofocal occlusion in the sigmoid sinus (Cases 4 and 5), bifocal occlusion in the sigmoid and the transverse sinuses (Cases 6-13) (Fig. 2), and culminated in the most complex and hazardous situation that involved the confluence of sinuses and/or bilateral lateral sinuses (Cases 14-17) (Figs. 3 and 4). The complex angioarchitecture of many of these lesions often makes both surgical and endovascular approaches problematic.

\section{Surgical Approach}

Surgical obliteration of the arterial supply and excision of the diseased segment of the dural sinus may be curative, but they are not acceptable as a standard treatment. The extremely abundant vascularity in the surrounding dura mater, skull, and overlying soft tissues causes tremendous intraoperative blood loss and leads to a high incidence of complications.[28,34] Moreover, preexisting brain swelling and hyperemia are occasionally aggravated by surgery, with consequent hemorrhagic complications. Some authors have stressed 
the need to take great precautions and make necessary preparations to protect against the possibility of potentially catastrophic hemorrhage during scalp-flap reflection, soft-tissue dissection, and craniotomy.[28,33]

\section{Endovascular Approach}

Standard endovascular approaches for this high-risk lesion are usually difficult and marked by failure.[7,15,19] Transarterial embolization using particulate embolic agents usually does not completely close the fistula because of the multitude of small arterial pedicles that supply the lesion.[2,16] There is also a high incidence of recanalization with particulate emboli. Although liquid embolic materials provide more stable results, they are associated with a higher risk of embolic penetration into the cortical veins or nutrient vessels of the cranial nerves, with a resultant focal neurological deficit and cranial nerve palsy, respectively.[6]

Transvenous embolization plays a key role in the curative treatment of DAVF. $[3,16,33,37]$ The diseased segment of the venous sinus can be accessed with a microcatheter via transfemoral approach in cases with unifocal occlusion such as in Cases 4 and 5. This was not an option in Cases 6 to 15 and 17, however, because the bifocal occlusion of the venous sinuses caused complete segregation of the diseased segment from the rest of the sinuses.

\section{Combined Endovascular-Surgical Approach}

According to a metaanalysis of the literature relevant to DAVFs, combined endovascular-surgical treatment has proved significantly more effective than either therapy alone in treating DAVFs of the transverse and sigmoid sinuses.[23] Our protocol for the combined treatment of high-risk DAVFs with occlusive change in the lateral sinus and confluence of sinuses consisted of 1) embolization of the feeding pedicles, 2) embolization of the diseased segment of the venous sinus, and 3) complementary surgical procedures (see Clinical Material and Methods section).

Transarterial Embolization. The value of transarterial embolization in the treatment of DAVF is controversial, and in recent years, much emphasis has been placed on the embolization of the diseased segment of the venous sinus.[16,33,37] However, as was shown in our cases, preoperative transarterial embolization using PVA particles is a simple and useful adjunct that effectively reduced arterial inflow and facilitated operative exposure of the involved segment of the dural sinuses. Particularly in the treatment of high-flow DAVFs, shunted blood should be reduced by transarterial embolization as an initial step. The reason is that when faced with abundant inflow through the fistula, packing the venous sinuses with occlusion coils may sometimes result in coil migration, incomplete obliteration, or even increased risk of venous infarction and intracranial hemorrhage resulting from the inadvertent diversion of arterialized blood into the cortical veins. $[6,17,35]$ In performing extensive transarterial embolization via the venous approach, there is no fear of losing sight of the entire abnormal segment. The reason for this is that the DAVFs are kept opacified from the arterial branches that are inaccessible by catheter techniques, because of the many feeding arteries. Devascularization of DAVFs by the transarterial approach is especially difficult when treating recurrent lesions, because feeding pedicles often reconstitute through complex collateral channels from extracranial arteries. Additional participation of the tentorial and dural branches arising from the ICA and VBA systems is common (Fig. 2). Embolization of these branches markedly reduces shunted blood in some cases; however, this is a risky procedure due to the possibility of reflux of the embolic material into the intracranial circulation. The only viable way to perform this safely is for an experinced technician to inject a small amount of NBCA diluted with oily contrast material under the guidance of high-resolution control digital subtraction angiography. The PVA particles cannot be used for this purpose because they are invisible. In cases improperly treated by surgical or endovascular ligation of the ECA, abundant collateral branches are 
established to the feeding pedicles from the muscular branches of the VA (Fig. 2). In this situation, intracranial VB branches are usually fed by the contralateral VA, and muscular branches are embolized by PVA particles following occlusion of the VA by using detachable balloons before the origin of the posterior inferior cerebellar artery. If the patient cannot tolerate test occlusion of the VA, the branches can be embolized with PVA particles, under temporary balloon occlusion of the VA above, followed by copious washing out of the dead space prior to balloon deflation to alleviate the possibility of scattering PVA particles into intracranial circulation.

Intraoperative Embolization. In intraoperative embolization procedures, one of the major advantages is that large fibered coils which are much less expensive and more thrombogenic than thin platinum coils, can be used for effective packing of the diseased segment of the sinus. The second advantage is that the sigmoid sinus can be easily embolized, which obviates the need for extensive surgical exposure of the sigmoid sinus, which is otherwise necessary to obliterate numerous small feeding vessels coming to the fistula directly through the mastoid and petrous bones.[28] Injection of liquid adhesive directly into the dural sinus should be avoided because of the high possibility of causing an infarct related to migration of the embolic material into the cortical vein or artery.[3] As a result of transvenous embolization, regression of the inaccessible arterial supply of arteries, such as the numerous leptomeningeal arteries and tentorial branches of the ICA and VBA systems, takes place (Figs. 1 and 2). Concomitantly, there is also a marked diminution of preexisting brain hyperemia.

Complementary Surgical Procedures. In many cases DAVF tends to persist or recur despite surgical intervention. As Fransen, et al.,[12] have pointed out in a detailed description, incomplete embolization and surgical devascularization fail to halt the progression of extensive DAVFs of the transverse sinuses. In our experience, there was occasional prompt recruitment of blood supply via the leptomeningeal vessels after completely surgically isolating the diseased segment of the dural sinus from the surrounding dura mater (Fig. 4). Additionally, it has been reported that even with combined therapy, more than $30 \%$ of cases will demonstrate residual filling.[23] Therefore, if intra- or postoperative control angiography reveals persistent filling of the fistula, we should proceed from intraoperative packing of the diseased segment to surgical isolation or resection to achieve complete cure. In these procedure, the most essential factor is the identification and ligation or clipping of cortical veins. All veins involved in the abnormal segment of the lateral sinus with bifocal occlusion should be ligated or clipped. This is necessary because the transverse sinus receives many cortical veins from the supra- and infratentorial structures. Therefore, if only those cortical veins with apparent retrograde filling are clipped after insufficient embolization, rerouting of the fistulous output and overloading would occur in the other untouched cortical veins.[30] These surgical procedures can be safely performed if arteriovenous shunt, degree of venous engorgement, and the size of the venous bed that is recruited by the fistula are progressively decreased by transarterial embolization and embolization of the diseased segment of the venous sinus. Administration of low-dose heparin for a few days postprocedure may be effective in alleviating the extension of thrombosis into the functioning cortical veins, which is occasionally seen after clipping the LRVD.[8]

\section{CONCLUSIONS}

It is believed that the treatment goal of potentially hazardous, complex DAVF of the lateral sinus and confluence of sinuses should be the complete obliteration of the lesion at the initial stage. These lesions are grouped by type into three angiographic categories: 1) extremely high flow DAVF without sinus occlusion and LRVD, which is best treated by transarterial embolization combined with transvenous occlusion, followed by resection of the diseased section of the sinus or surgical isolation of the segment and irradiation, 2) localized DAVF with exclusive LRVD, which is best treated by transarterial embolization combined with surgical disconnection of LRVD, and 3) DAVF with bifocal or diffuse sinus occlusion and LRVD, which is 
best treated by transarterial embolization combined with tight packing of the segregated sinus with or without complementary surgical isolation or resection of the lesion.

Of course, the least intrusive course is the most desirable, but usually that option is not totally successful. Incomplete embolization and surgical devascularization reduce the risk factors only temporarily, fail to halt progression, and make subsequent treatment difficult.[34,38]

\section{Acknowledgments}

The authors wish to thank Dr. Kiyoshi Ihara from Tokuyama Chuo-Hospital, and Drs. Akira Tanaka and Takeo Fukushima from Fukuoka University for their surgical assistance. Also the authors wish to express appreciation to Dr. Winston E.H. Lim from Singapore General Hospital, Singapore, Dr. Cheng Pui Wai from Queen Mary Hospital, Hong Kong, and Mr. Stephen Cotton and Mr. Christopher Muffett of the International Training Program in Iizuka Hospital for manuscript preparation.

\section{References}

1. Awad IA, Little JR, Akrawi WP, et al: Intracranial dural arteriovenous malformations: factors predisposing to an aggressive neurological course. J Neurosurg 72:839-850, 1990

2. Barnwell SL, Halbach VV, Dowd CF, et al: A variant of arteriovenous fistulas within the wall of dural sinuses. Results of combined surgical and endovascular therapy. J Neurosurg 74:199-204,1991

3. Barnwell SL, Halbach VV, Higashida RT, et al: Complex dural arteriovenous fistulas. Results of combined endovascular and neurosurgical treatment in 16 patients. J Neurosurg 71:352-358, 1989

4. Borden JA, Wu JK, Shucart WA: A proposed classification for spinal and cranial dural arteriovenous fistulous malformations and implications for treatment. J Neurosurg 82:166-179, 1995

5. Castaigne P, Bories J, Brunet P, et al: [Meningeal arterio-venous fistulas with cortical venous drainage.] Rev Neurol 132:169-181, 1976 (Fr)

6. Cognard C, Gobin YP, Pierot L, et al: Cerebral dural arteriovenous fistulas: clinical and angiographic correlation with revised classification of venous drainage. Radiology 194:671-680, 1995

7. Collice M, D'Aliberti G, Talamonti G, et al: Surgical interruption of leptomeningeal drainage as treatment for intracranial dural arteriovenous fistulas without dural sinus drainage. J Neurosurg 84:810-817, 1996

8. Davies MA, Saleh J, Ter Brugge K, et al: The natural history and management of intracranial dural arteriovenous fistulae. Part 1: Benign lesions. Intervent Neuroradiol 3:295-302, 1997

9. Davies MA, Saleh J, Ter Brugge K, et al: The natural history and management of intracranial dural arteriovenous fistulae. Part 2: Aggressive lesions. Intervent Neuroradiol 3:303-311, 1997

10. Davies MA, Ter Brugge K, Willinski R, et al: The validity of classification for the clinical presentation of intracranial dural arteriovenous fistulas. J Neurosurg 85:830-837, 1996

11. Djindjian R, Merland JJ, Theron J: B>Super-Selective Arteriography of the External Carotid Artery.Berlin: Springer-Verlag, 1978, pp. 405-406

12. Fransen $P$, Mathurin P, Pierre $P$, et al: Interest and necessity of combined neuroradiological and neurosurgical treatment in some cases of dural arterio-venous fistulae. Acta Neurochir 121:26-33, 1993 
13. Graeb DA, Dolman CL: Radiological and pathological aspects of dural arteriovenous fistulas. Case report. J Neurosurg 64:962-967, 1986

14. Grisoli F, Vincentelli F, Fuchs S, et al: Surgical treatment of tentorial arteriovenous malformations draining into the subarachnoid space. Report of four cases. J Neurosurg 60:1059-1066, 1984

15. Halbach VV, Higashida RT, Hieshima GB, et al: Dural fistulas involving the transverse and sigmoid sinuses: results of treatment in 28 patients. Radiology 163:443-447, 1987

16. Halbach VV, Higashida RT, Hieshima GB, et al: Transvenous embolization of dural fistulas involving transverse and sigmoid sinuses. AJNR 10:385-392, 1989

17. Hamada Y, Goto K, Inoue T, et al: Histopathological aspect of dural arteriovenous fistulas in the transverse-sigmoid sinus region in nine patients. Neurosurgery 40:452-458, 1997

18. Houser OW, Baker HL Jr, Rhoton AL Jr, et al: Intracranial dural arteriovenous malformations. Radiology 105:55-64, 1972

19. Ishii K, Goto K, Ihara K, et al: High-risk dural arteriovenous fistulae of the transverse and sigmoid sinuses. AJNR 8 : 1113-1120, 1987

20. Lalwani AK, Dowd CF, Halbach VV: Grading venous restrictive disease in patients with dural arteriovenous fistulas of the transverse/sigmoid sinus. J Neurosurg 79:11-15, 1993

21. Lasjaunias P: Editorial comment on Davies' papers. Angioarchitecture and natural history of dural arteriovenous shunts. Intervent Neuroradiol 3:313-317, 1997

22. Lasjaunias P, Chiu M, Ter Brugge K, et al: Neurological manifestations of intracranial dural arteriovenous malformations. J Neurosurg 64:724-730, 1986

23. Lucas CP, Zabramski JM, Spetzler RF, et al: Treatment for intracranial dural arteriovenous

malformations: a meta-analysis from the English language literature. Neurosurgery 40:1119-1132, 1997

24. Malik GM, Pearce JE, Ausman JI, et al: Dural arteriovenous malformations and intracranial hemorrhage. Neurosurgery 15:332-339, 1984

25. Matsushima T, Rhoton AL Jr, de Oliveira E, et al: Microsurgical anatomy of the veins of the posterior fossa. J Neurosurg 59:63-105, 1983

26. Matsushima T, Suzuki SO, Fukui M, et al: Microsurgical anatomy of the tentorial sinuses. J Neurosurg 71:923-928, 1989

27. Nishijima M, Takaku A, Endo S, et al: Etiological evaluation of dural arteriovenous malformations of the lateral and sigmoid sinuses based on histopathological examinations. J Neurosurg 76:600-606, 1992

28. Ojemann RG, Heros RC, Crowell RM: Surgical Management of Cerebrovascular Disease. Baltimore: Williams \& Wilkins, 1988, pp 415-425

29. Oka K, Rhoton AL Jr, Barry M, et al: Microsurgical anatomy of the superficial veins of the cerebrum. Neurosurgery 17:711-748, 1985

30. Pierot L, Chiras J, Meder JF, et al: Dural arteriovenous fistulas of the posterior fossa draining into subarachnoid veins. AJNR 13:315-323, 1992 
31. Piske RL, Lasjaunias P: Extrasinusal arteriovenous malformations. Report of three cases.

Neuroradiology 30:426-432, 1988

32. Piton J, Guilleux MH, Guibert-Tranier F, et al: Fistulae of the lateral sinus. J Neuroradiol 11:143-159, 1984

33. Roy D, Raymond J: The role of transvenous embolization in the treatment of intracranial dural arteriovenous fistulas. Neurosurgery 40:1133-1144, 1997

34. Sundt TM Jr, Piepgras DG: The surgical approach to arteriovenous malfomations of the lateral and sigmoid dural sinuses. J Neurosurg 59:32-39, 1983

35. Tanaka A, Fukushima T, Tomonaga M: Intracerebral hematomas in cases of dural arteriovenous malformation and carotid-cavernous fistula. Surg Neurol 25:557-562, 1986

36. Thompson BG, Doppman JL, Oldfield EH: Treatment of cranial dural arteriovenous fistulae by interruption of leptomeningeal venous drainage. J Neurosurg 80:617-623, 1994

37. Urtasun F, Biondi A, Casasco A, et al: Cerebral dural arteriovenous fistulas: percutaneus transvenous embolization. Radiology 199:209-217, 1996

38. Viñuela F, Fox AJ, Pelz DM, et al: Unusual clinical manifestations of dural arteriovenous malformations. J Neurosurg 64:554-558, 1986

Manuscript received August 11, 1998.

Accepted in final form September 15, 1998.

Address reprint requests to: Katsuya Goto., M.D., Ph.D., Department of Interventional Neuroradiology, Iizuka Hospital, 3-83 Yoshio-machi, Iizuka 820-8505, Japan. email: k-goto@mars.dti.ne.jp 